\title{
A Potent Antagonist of Protease-Activated Receptor 2 That Inhibits Multiple Signaling Functions in Human Cancer Cells ${ }^{[\mathbf{s}}$
}

\author{
Yuhong Jiang, Mei-Kwan Yau, Junxian Lim, Kai-Chen Wu, Weijun Xu, Jacky Y. Suen, \\ and David P. Fairlie \\ Centre for Inflammation and Disease Research and Australian Research Council Centre of Excellence in Advanced Molecular \\ Imaging, Institute for Molecular Bioscience, University of Queensland, Brisbane, Queensland, Australia
}

Received September 4, 2017; accepted December 4, 2017

\begin{abstract}
Protease-activated receptor 2 (PAR2) is a cell surface protein linked to G-protein dependent and independent intracellular signaling pathways that produce a wide range of physiological responses, including those related to metabolism, inflammation, pain, and cancer. Certain proteases, peptides, and nonpeptides are known to potently activate PAR2. However, no effective potent PAR2 antagonists have been reported yet despite their anticipated therapeutic potential. This study investigates antagonism of key PAR2-dependent signaling properties and functions by the imidazopyridazine compound I-191 (4-(8-(tert-butyl)-6-(4-fluorophenyl)imidazo[1,2-b]pyridazine2-carbonyl)-3,3-dimethylpiperazin-2-one) in cancer cells. At nanomolar concentrations, I-191 inhibited PAR2 binding of and activation by structurally distinct PAR2 agonists (trypsin, peptide, nonpeptide) in a concentration-dependent manner in cells of the human colon adenocarcinoma grade II cell line (HT29). I-191 potently attenuated multiple PAR2-mediated intracellular signaling pathways leading to $\mathrm{Ca}^{2+}$ release, extracellular signal-regulated kinase 1/2 (ERK1/2) phosphorylation, Ras
\end{abstract}

homologue gene family, member $A($ RhoA) activation, and inhibition of forskolin-induced cAMP accumulation. The mechanism of action of $\mathrm{I}-191$ was investigated using binding and calcium mobilization studies in HT29 cells where I-191 was shown to be noncompetitive and a negative allosteric modulator of the agonist 2f-LIGRL-NH . The compound alone did not activate these PAR2-mediated pathways, even at high micromolar concentrations, indicating no bias in these signaling properties. I-191 also potently inhibited PAR2-mediated downstream functional responses, including expression and secretion of inflammatory cytokines and cell apoptosis and migration, in human colon adenocarcinoma grade II cell line (HT29) and human breast adenocarcinoma cells (MDA-MB-231). These findings indicate that I-191 is a potent PAR2 antagonist that inhibits multiple PAR2-induced signaling pathways and functional responses. I-191 may be a valuable tool for characterizing PAR2 functions in cancer and in other cellular, physiological, and disease settings.

\section{Introduction}

Protease-activated receptors (PARs) are unusual rhodopsinlike G-protein coupled receptors (GPCRs) in being activated by proteases (e.g., trypsin, thrombin), which cleave within the extracellular $\mathrm{N}$ terminus to expose an activating sequence

This work was supported by the National Health and Medical Research Council for Senior Principal Research Fellowships [Grant 1027369, 1117017] and project grants [Grant 1084083, 1047759] and the Australian Research Council [Grant DP130100629, CE140100011] (to D.P.F.)

https://doi.org/10.1124/jpet.117.245027.

S This article has supplemental material available at jpet.aspetjournals.org.
(Coughlin, 2000; Arora et al., 2007; Tuteja, 2009; Yau et al., 2013). Protease-activated receptor 2 (PAR2) is the most highly expressed PAR in certain immune and cancer cells. Upon activation, PAR2 mediates intracellular coupling to heterotrimeric $\mathrm{G}$ proteins that trigger pathway-dependent signaling (e.g., $\mathrm{Ca}^{2+}$ release, extracellular signal-regulated kinase 1/2 [ERK1/2] phosphorylation, Ras homologue gene family, member A [RhoA] activation) as well as G protein-independent $\beta$-arrestin 1/2 signaling (Rothmeier and Ruf, 2012; Suen et al., 2014). PAR2 signaling pathways are involved in circulatory, cardiovascular, central nervous, gastrointestinal, metabolic, and respiratory systems (Ossovskaya and Bunnett, 2004;

ABBREVIATIONS: AZ3451, 2-(6-bromo-1,3-benzodioxol-5-yl)- $N$-(4-cyanophenyl)-1-[(1S)-1-cyclohexylethyl]benzimidazole-5-carboxamide; AZ8838, (S)-(4-fluoro-2-propylphenyl)-(1H-imidazol-2-yl)methanol; BSA, bovine serum albumin; AY77, 5-lsoxazoyl-Cha-Chg-NH ${ }_{2}$; C391, (2S)-6-amino-N-((S)-1(((S)-1-amino-3-(4-hydroxyphenyl)-1-oxopropan-2-yl)amino)-4-methyl-1-oxopentan-2-yl)-2-((3S)-1-(furan-2-carbonyl)-3-(3-methylbutanamido)-

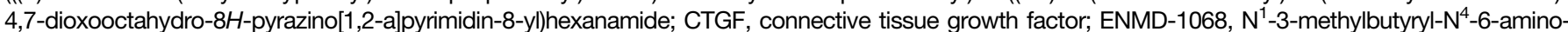
hexanoyl-pipera-zine; ERK, extracellular signal-regulated kinase; FBS, fetal bovine serum; GB83, 5-Isoxazoyl-Cha-lle-spiroindane-1,4'-piperidine; GB88, 5-Isoxazoyl-Cha-Ile-spiroindene-1,4'-piperidine; GB110, 5-Isoxazoyl-Cha-lle-(3-[aminomethyl]phenyl)-(4-[aminomethyl]piperidin-1- yl)methanone; GPCRs, G-protein coupled receptors; HBSS, Hanks' balanced salt solution; HT29, human colon adenocarcinoma grade II cell line; I-191, 4-(8-(tert-butyl)-6-(4fluorophenyl)imidazo[1,2-b]pyridazine-2-carbonyl)-3,3-dimethylpiperazin-2-one; IL-6, interleukin-6; IL-8, interleukin-8; IFN- $\gamma$, interferon $\gamma$; K-14585, \{N-[1-(2,6dichlorophenyl)methyl]-3-(1-pyrrolidinylmethyl)-1H-indol-5-yl\}aminocarbonyl\}-glycinyl-L-lysinyl-L-phenylalanyle-N-benzhydrylamide; MDA-MB-231, human breast adenocarcinoma cells; PARs, protease-activated receptors; PAR2, protease-activated receptor 2; PBS, phosphate-buffered saline; RhoA, Ras homologue gene family, member A; SLIGRL-NH ${ }_{2}$, H-Ser-Leu-lle-Gly-Arg-Leu-NH ${ }_{2}$; TNF, tumor necrosis factor. 
Saito and Bunnett, 2005; Lam and Schmidt, 2010; Rothmeier and Ruf, 2012). The consequent modulation by PAR2 of a wide range of physiological and disease processes in these tissues, including inflammation, cancer, and respiratory and central nervous system dysfunction, highlights PAR2 as a potential unexploited therapeutic target (Knight et al., 2001; Reed et al., 2003; Matej et al., 2007).

PAR2 is mainly activated by serine proteases (e.g., trypsin, tryptase, TF-FVIIa-FXa, matriptase) (Darmoul et al., 2004; Seitz et al., 2007; McLarty et al., 2011; Ramachandran et al., 2011; Mihara et al., 2016), while some proteases cleave at a noncanonical site to produce a different activating sequence and different signaling profiles (Hollenberg et al., 2014; Zhao et al., 2015). Synthetic peptides also activate PAR2 (e.g., H-Ser-Leu-Ile-Gly-Arg-Leu-NH [SLIGRL-NH $_{2}$ ], 2-furoyl-LIGRL$\mathrm{NH}_{2}$ ) (Kawabata et al., 2005; Barry et al., 2010; Yau et al., 2015), some being biased agonists (e.g., 2f-LAAAAI-NH ${ }_{2}$, Isox-Cha-Chg$\mathrm{NH}_{2}$, Isox-Cha-Chg-Ala-Arg- $\mathrm{NH}_{2}$ ) that signal more effectively through one pathway than another (Jiang et al., 2017). The beneficial effects of PAR2 activation in vivo remain uncertain and context dependent, with pathway-selective biased ligands potentially being helpful in elucidating and harnessing therapeutic potential.

PAR2 antagonists might have disease-modifying properties, but only a few weakly potent antagonists are known to test this possibility. ENMD-1068 (N $\mathrm{N}^{1}-3$-methylbutyryl-N ${ }^{4}-6$-aminohexanoyl-pipera-zine) weakly inhibits PAR2-mediated $\mathrm{Ca}^{2+}$ signaling in vitro ( $\mathrm{IC}^{50} 5 \mathrm{mM}$ ) and joint inflammation in vivo (Kelso et al., 2006), although it is uncertain if this is via PAR2. K-14585 (\{N-[1-(2,6-dichlorophenyl)methyl]-3-(1-pyrrolidinylmethyl)-1Hindol-5-yl)aminocarbonyl\}-glycinyl-L-lysinyl-L-phenylalanyle-N-benzhydrylamide), a more potent peptidic PAR2 antagonist, inhibits p38 mitogen-activated protein kinase activation and interleukin 8 (IL-8) secretion, but promotes them above $10 \mu \mathrm{M}$ concentrations (Goh et al., 2009). GB83 (5Isoxazoyl-Cha-Ile-spiroindane-1,4'-piperidine) and GB88 (5Isoxazoyl-Cha-Ile-spiroindene-1,4'-piperidine) ( $\left.\mathrm{IC}_{50} 1-10 \mu \mathrm{M}\right)$ and analogs inhibit PAR2 activation by proteases (e.g., trypsin, tryptase), peptides (e.g., SLIGRL-NH $\mathrm{N}_{2}$, 2-furoyl-LIGRLO$\mathrm{NH}_{2}$ ), and nonpeptides (e.g., GB110, 5-Isoxazoyl-Cha-Ile-(3-[aminomethyl]phenyl)-(4-[aminomethyl]piperidin-1- yl)methanone) as measured by $\mathrm{Ca}^{2+}$ release in multiple cell types (Barry et al., 2010; Suen et al., 2012; Yau et al., 2016b). Although GB88 is an antagonist in inhibiting PAR2-induced calcium mobilization, it is an agonist in stimulating RhoA activation, promoting ERK1/2 phosphorylation, and reducing forskolinstimulated cAMP (Suen et al., 2014). A different peptidomimetic C391 (2S)-6-amino-N-((S)-1-(((S)-1-amino-3-(4-hydroxyphenyl)-1oxopropan-2-yl)amino)-4-methyl-1-oxopentan-2-yl)-2- ((3S)-1-(furan2-carbonyl)-3-(3-methylbutanamido)-4,7-dioxooctahydro-8Hpyrazino[1,2-a]pyrimidin-8-yl)hexanamide] is a weak PAR2 antagonist of $\mathrm{Ca}^{2+}\left(\mathrm{IC}_{50} 1.3 \mu \mathrm{M}\right)$ and pERK ( $\left.\mathrm{IC}_{50} 14 \mu \mathrm{M}\right)$ signaling, as well as pain responses in vivo (Boitano et al., 2015). Heptares and Astra-Zeneca reported an imidazole ((S)(4-fluoro-2-propylphenyl)-(1H-imidazol-2-yl)methanol [AZ8838], $\mathrm{IC}_{50} 4.2 \mu \mathrm{M}$ vs. trypsin; $2.3 \mu \mathrm{M}$ vs. SLIGRL) and a benzimidazole (2-(6-bromo-1,3-benzodioxol-5-yl)- $N$-(4-cyanophenyl)-1-[(1S)1-cyclohexylethyl]benzimidazole-5-carboxamide [AZ3451], $\mathrm{IC}_{50} 6.6 \mu \mathrm{M}$ vs. trypsin; $5.4 \mathrm{nM}$ vs. SLIGRL) that bind at different sites in PAR2 crystal structures and inhibit $\mathrm{Ca}^{2+}$ (Cheng et al., 2017). In summary, most PAR2 antagonists are active at only micromolar concentrations and do not inhibit all types of PAR2 agonists (proteases, peptides, nonpeptides); their activity can be context and cell dependent, or they have only been reported to date to be capable of inhibiting $\mathrm{Ca}^{2+}$ signaling (Yau et al., 2016a,b).

A diverse series of imidazopyridazine derivatives was recently claimed in a patent to antagonize PAR2-induced intracellular $\mathrm{Ca}^{2+}$ release at micromolar-nanomolar concentrations (Farmer et al., 2015), although there was no evidence supporting selective binding to PAR2. Here we show that one imidazopyridazine derivative, I-191 [4-(8-(tert-butyl)-6-(4fluorophenyl)imidazo[1,2-b] pyridazine-2-carbonyl)-3,3dimethylpiperazin-2-one] displaces the binding of a fluorescent agonist from PAR2 and inhibits multiple PAR2-mediated signaling pathways and related functions in colorectal and breast carcinoma cells. I-191 is a full antagonist, with no agonist activity alone, of both trypsin- and peptide-(2f-LIGRL$\mathrm{NH}_{2}$ )-induced $\mathrm{Ca}^{2+}$ release, ERK1/2 phosphorylation, RhoA activation, and inhibition of forskolin-induced cAMP accumulation in the human colon adenocarcinoma grade II HT29 cell line. Furthermore, I-191 also inhibits ERK1/2 phosphorylation, RhoA activation, and inhibition of forskolin-stimulated cAMP accumulation induced by micromolar concentrations of biased ligand GB88. The antagonist function of I-191 is established here by 1) inhibition of PAR2-induced expression of inflammatory genes and proteins that have been previously associated with PAR2 activation, 2) inhibition of PAR2reduced apoptosis-related caspase cleavages, and 3) inhibition of PAR2-triggered migration of HT29 or human breast adenocarcinoma MDA-MB-231 cells. These findings indicate that I-191 is a potentially valuable tool in vitro for probing roles of PAR2 in physiology.

\section{Materials and Methods}

Cell Culture. All cell culture reagents were purchased from Invitrogen (Carlsbad, CA) and Sigma-Aldrich (St. Louis, MO). The HT29 and MDA-MB-231 cells were a gift from the Queensland Medical Research Institute (Brisbane, Australia). HT29 cells were maintained in Dulbecco's modified Eagle's medium at $37^{\circ} \mathrm{C}$ and $5 \% \mathrm{CO}_{2}$, and the MDA-MB-231 cells were cultured in Leibovitz's L15 medium at $37^{\circ} \mathrm{C}$ without $\mathrm{CO}_{2}$. All media were supplemented with $10 \%$ fetal bovine serum (FBS), $100 \mathrm{U} / \mathrm{ml}$ penicillin, and $100 \mathrm{U} / \mathrm{ml}$ streptomycin.

Binding Assay. Assays were performed as previously described elsewhere (Hoffman et al., 2012; Suen et al., 2014). The cells were seeded overnight in a 384-well plate at $2.4 \times 10^{4}$ cells/well, followed by phosphate-buffered saline (PBS) with $2 \%$ bovine serum albumin (BSA) blocking for 1 hour at $37^{\circ} \mathrm{C}$. The cells were simultaneously exposed to 2f-LIGRLO (diethylenetriaminepentaacetate-europium)$\mathrm{NH}_{2}(300 \mathrm{nM})$ and PAR2 ligands for 30 minutes. The cells were washed with PBS mixed with $20 \mu \mathrm{M}$ EDTA, 0.01\% Tween and $0.2 \%$ BSA. Finally, the cells were incubated with DELFIA enhancement solution (Perkin Elmer, Waltham, MA) for 90 minutes. Fluorescence was measured using a Pherastar FS fluorimeter (BMG Labtech, Ortenberg, Germany).

Intracellular Calcium Mobilization. Cells were seeded overnight in 96-well plates at $5 \times 10^{4}$ cells/well and then incubated in dye loading buffer (Hanks' balanced salt solution [HBSS] with $4 \mu \mathrm{M}$ Fluo$3,0.04 \%$ pluronic acid, $1 \% \mathrm{FBS}$ and $2.5 \mathrm{mM}$ probenecid) for 1 hour at $37^{\circ} \mathrm{C}$. The cells were washed with HBSS before adding antagonists for 30 minutes. The plates were transferred to a FLIPR Tetra instrument (Molecular Devices, Sunnyvale, CA). PAR2 agonists were added 10 seconds after reading commenced, and the calcium signals were measured in real time (excitation at $480 \mathrm{~nm}$ and emission at $520 \mathrm{~nm}$ ). Receptor residence time was determined by washout experiments. 
Antagonists were preincubated with cells for 30 minutes at $37^{\circ} \mathrm{C}$; then unbound antagonists were removed by washing with HBSS buffer. At every indicated time point, the plates were read after agonist addition. We used 2f-LIGRL- $\mathrm{NH}_{2}$ alone $(5 \mu \mathrm{M})$ to measure maximum fluorescence due to $\mathrm{Ca}^{2+}$ sequestration by Fluo-3, with individual results normalized accordingly.

The agonist concentration-response curves with increasing concentration of antagonists were fitted to an operational model of allosterism (Gregory et al., 2012; Kenakin, 2013):

$$
\text { Effect }=\frac{E_{m}\left[\tau_{A}[\mathrm{~A}]\left(K_{\mathrm{B}}+\alpha \beta[\mathrm{B}]+\tau_{\mathrm{B}}[\mathrm{B}] K_{\mathrm{A}}\right)\right]^{n}}{\left([\mathrm{~A}] K_{\mathrm{B}}+K_{\mathrm{A}} K_{\mathrm{B}}+K_{\mathrm{A}}[\mathrm{B}]+\alpha[\mathrm{A}][\mathrm{B}]\right)^{n}+\left[\tau_{\mathrm{A}}[\mathrm{A}]\left(K_{\mathrm{B}}+\alpha \beta[\mathrm{B}]\right)+\tau_{\mathrm{B}}[\mathrm{B}] K_{\mathrm{A}}\right]^{n}}
$$

where $E_{m}$ is the maximum possible response, [A] is the molar concentration of agonist 2f-LIGRL- $\mathrm{NH}_{2}, K_{\mathrm{A}}$ is the equilibrium dissociation constant of agonist $2 \mathrm{f}-\mathrm{LIGRL}-\mathrm{NH}_{2},[\mathrm{~B}]$ is the molar concentration, and $K_{\mathrm{B}}$ is the equilibrium dissociation constant for the allosteric modulator. The cooperativity factor $\alpha$ is related to the affinity of the agonist, $\beta$ represents the efficacy of the agonist, and $\tau_{\mathrm{A}}$ and $\tau_{\mathrm{B}}$ represent the capacity of the agonist and allosteric modulator to regulate receptor activation, respectively. Because I-191 showed no agonist activity, $\tau_{\mathrm{B}}=0$, and the formula simplified to:

$$
\text { Effect }=\frac{E_{m}\left[\tau_{\mathrm{A}}[\mathrm{A}]\left(K_{\mathrm{B}}+\alpha \beta[\mathrm{B}]\right)\right]^{n}}{\left([\mathrm{~A}] K_{\mathrm{B}}+K_{\mathrm{A}} K_{\mathrm{B}}+K_{\mathrm{A}}[\mathrm{B}]+\alpha[\mathrm{A}][\mathrm{B}]\right)^{n}+\left[\tau_{\mathrm{A}}[\mathrm{A}]\left(K_{\mathrm{B}}+\alpha \beta[\mathrm{B}]\right)\right]^{n}}
$$

The parameters that were held constant were $K_{\mathrm{A}}=10^{-7}, K_{\mathrm{B}}=10^{-8}$, $\tau_{\mathrm{A}}=10$, and $E_{m}=100$.

AlphaLISA Surefire pERK1/2 Assay. Cells were seeded overnight in 384-well proxiplates at $2 \times 10^{3}$ cells/well and then were serum-starved for 2 hours at $37^{\circ} \mathrm{C}$ before treatment with PAR2 ligands dissolved in serum-free medium. The antagonists were preincubated for 10 minutes followed by stimulation with the agonist for 10 minutes. The supernatant was removed, and cell lysis buffer was added with shaking for 30 minutes at room temperature, followed by adding reaction mixture for 2 hours. Phosphorylation of ERK1/2 was measured according to the manufacturer's instructions (PerkinElmer) and was read using a Pherastar FS fluorimeter (BMG Labtech).

G-LISA RhoA Activation. The cells were seeded at $2 \times 10^{5}$ cells/well and were serum-starved for 2 days. After treatment with a PAR2 agonist for 20 minutes at $37^{\circ} \mathrm{C}$, the cells were lysed for RhoA detection. An antagonist was added to the cells 1 hour before the agonist. RhoA activation was measured using a G-LISA Biochem kit according to the manufacturer's instructions (Cytoskeleton, Denver, $\mathrm{CO}$ ).

Briefly, cell lysates were added to the binding buffer and incubated at $4^{\circ} \mathrm{C}$ for 30 minutes. Antigen-presenting buffer was then added for 2 minutes after washing. The cells were incubated with anti-RhoA primary antibody for 45 minutes, and subsequently were incubated with secondary antibodies for 45 minutes. The mixed horseradish peroxidase detection reagent was added for 15 minutes then stopped with buffer before the signal was read by measuring the absorbance at $490 \mathrm{~nm}$ using a microplate spectrophotometer (Suen et al., 2014).

cAMP Accumulation Assay. The cells were seeded overnight in 384 -well proxiplates at $2.4 \times 10^{3}$ cells/well. The antagonists were preincubated for 10 minutes, followed by stimulation with agonist for 30 minutes before treatment with PAR2 agonists and forskolin for 30 minutes at room temperature. Next cAMP detection reagent was added for 1 hour at room temperature. The cAMP accumulation was measured according to the manufacturer's instructions (PerkinElmer) and read using a Pherastar FS fluorimeter (BMG Labtech).

Cytokine-Induced Cleavage of Caspases 3 and 8. As previously described elsewhere (Iablokov et al., 2014), the cells were seeded overnight at $5 \times 10^{5}$ cells per well. After serum starving for 1 hour, the cells were incubated for 30 minutes with different concentrations of a PAR2 antagonist before the addition of a PAR2 agonist. Caspase 3/8 cleavage was then induced through addition of interferon- $\gamma\left(\right.$ IFN- $\gamma, 40 \mathrm{ng} \mathrm{ml}^{-1}$ ) for 5 minutes before adding tumor necrosis factor (TNF, $10 \mathrm{ng} \mathrm{m}^{-1}$ ) and incubating for 6 hours more.

Immunoblot. After treatment, cell lysates were prepared using lysis buffer supplemented with a protease and phosphatase inhibitor cocktail (Cell Signaling Technology, Beverly, MA). Cell lysates were separated by electrophoresis in a Bolt Bis-Tris Plus $4 \%-12 \%$ gel (Thermo Fisher Scientific, Waltham, MA), followed by electrical transfer using the iBlot 2 Dry Blotting System (Thermo Fisher Scientific). The membranes were incubated with primary antibodies and secondary antibodies (cleaved caspase 3; Cell Signaling Technology 9661; cleaved caspase 8, Cell Signaling Tech 9496; anti-rabbit antibody conjugated to horseradish peroxidase; Cell Signaling Technology) using the iBind Western System (Life Technologies, Camarillo, CA) according to the manufacturer's instructions. Exposure times were varied to eliminate signal saturation. GAPDH (Sigma Aldrich) was used as a loading control, and the band intensity was calculated with ImageJ software (U.S. National Institutes of Health, Bethesda, MD).

Reverse-Transcription Polymerase Chain Reaction. The cells were seeded overnight at a density of $5 \times 10^{5}$ cells per well in 12 -well plates. The cells were serum-starved overnight then were preincubated with different antagonist concentrations for 30 minutes before adding a PAR2 agonist for 1 hour. The cells were then lysed, and RNA was isolated using the ISOLATE II RNA Mini Kit (Bioline, London, United Kingdom). Total RNA was extracted from the cells; random oligo dT were initially incubated at $70^{\circ} \mathrm{C}$ for 10 minutes, and then cooled on ice for at least 1 minute before being reverse transcribed with Superscript III (Invitrogen) at $50^{\circ} \mathrm{C}$ for 50 minutes then at $70^{\circ} \mathrm{C}$ for 10 minutes. Quantitative real-time polymerase chain reaction was performed using a ViiATM 7 Real-Time PCR System (Life Technologies, Carlsbad, CA), cDNA, SYBER Green master mix (Life Technologies), and primers. The genes were amplified for 40 cycles, and the relative gene expression was normalized against HPRT1 (forward: TCAGGCAGTATAATCCAAAGATGGT; reverse: AGTCTGGCTTATATCCAAC ACTTCG).

ELISA. The cells were seeded overnight at a density of $5 \times 10^{5}$ cells/well in 12-well plates. The cells were serum-starved overnight before exposure to various concentrations of an antagonist for 30 minutes. The cells were then treated with a PAR2 agonist for 24 hours. The cell supernatants were collected, and the cytokine secretion was measured using an ELISA for human IL-8, according to manufacturer's instructions (BD Biosciences, San Jose, CA).

Cell Migration In Vitro. HT29 cells were seeded overnight at a density of $2 \times 10^{5}$ cells/well in 12 -well plates. As described previously elsewhere (Lam and Schmidt, 2010), after cells formed a confluent monolayer, a scratch gap was created using a p200 pipette tip. The cells were washed to remove floating cells and were incubated with or without PAR2 agonists in serum-free medium. Antagonists were added for 30 minutes before scratching the monolayer. The images of the scratch gap were acquired (at 0,24 , and 48 hours) using a Nikon Ti-U inverted brightfield microscope (Nikon, Tokyo, Japan). The scratch gap size was calculated using ImageJ (U.S. National Institutes of Health). Scratch gap size was measured as the gap area at 48 hours divided by the initial gap area at 0 hours.

Transwell Chemotaxis Assay. The transwell system (polycarbonate filter insert with $8 \mu \mathrm{m}$ pore size membrane; Corning, Corning, NY) was used to investigate cell migration. Both sides of the membrane were coated with collagen I and air dried for 2 minutes. The cells were dissociated using nonenzymatic cell dissociation solution and resuspended in serum-free L-15 with $0.1 \%$ BSA. The cells were seeded $\left(2.5 \times 10^{5} /\right.$ insert $)$ and allowed to incubate for 3 hours at $37^{\circ} \mathrm{C}$. PAR2 ligands were diluted in serumfree L-15 with $0.1 \%$ BSA and added to the bottom chamber to stimulate cell migration. Antagonists were preincubated for 30 minutes in the upper chamber before agonist addition. The transwell plates were incubated at $37^{\circ} \mathrm{C}$, and the cells were allowed to migrate for 24 hours. 
A<smiles>CC(C)(C)c1cc(-c2ccc(F)cc2)nn2cc(C(=O)N3CCNC(=O)C3(C)[AlH2])nc12</smiles>

I-191

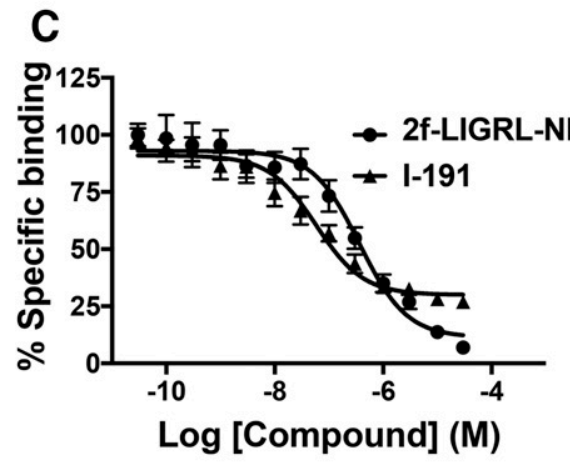

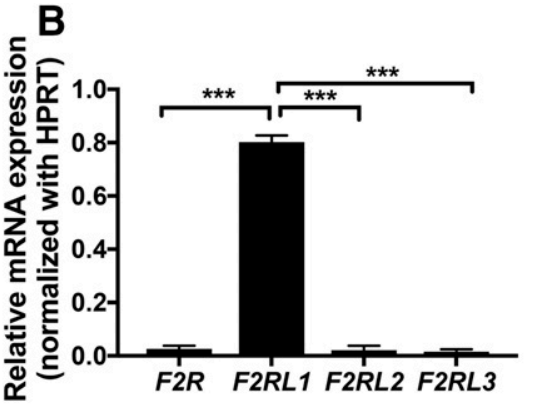

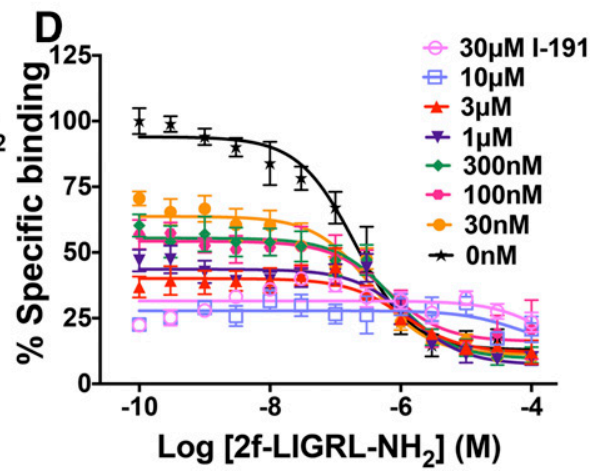

Fig. 1. Specific binding of I-191 to PAR2 in HT29 cells. (A) Structure of PAR2 ligand, I-191. (B) Relative human mRNA expression of PAR1-4 genes $(F 2 R, F 2 R L 1, F 2 R L 2, F 2 R L 3)$ in HT29 cells, PAR2 having the highest expression. (C) Concentration-dependent binding with $300 \mathrm{nM}$ Eu-labeled 2f-LIGRLO- $\mathrm{NH}_{2}$ of 2f-LIGRL- $\mathrm{NH}_{2}$ $\left(\mathrm{pIC}_{50} 6.4 \pm 0.2\right)$ or $\mathrm{I}-191\left(\mathrm{pIC}_{50} 7.1 \pm 0.2\right) .2 \mathrm{f}-$ LIGRLO-NH $\mathrm{N}_{2}$ and 2f-LIGRL-NH $\mathrm{N}_{2}$ are wellestablished PAR2-selective agonist ligands. (D) Concentration-dependent response of $2 \mathrm{f}$ LIGRL- $\mathrm{NH}_{2}$ in displacing $300 \mathrm{nM}$ Eu-tagged $2 \mathrm{f}-\mathrm{LIGRLO}-\mathrm{NH}_{2}$ binding to PAR2, in the presence of increasing concentrations of I-191 in HT29 cells. Statistical analysis was by oneway analysis of variance followed by Dunnett's multiple comparisons test, each data point representing the mean \pm S.E.M. $* * * P<0.001$ $(n \geq 3)$.
After incubation, the cells in the top chamber of the membrane were removed carefully using a cotton swab and fixed in $4 \%$ paraformaldehyde. The membrane was washed twice with PBS and stained with 4,6-diamidino-2-phenylindole. Migrated cells on the underside of the membrane were counted using a Nikon Ti-U inverted brightfield microscope.

Statistical Analysis. GraphPad Prism 7.0 (GraphPad Software, San Diego, CA) was used to analyze all data. Statistically significance of differences between groups were measured using one-way analysis of variance, followed by Dunnett's multiple comparisons test or Student's $t$ test. Data are presented as the mean of the entire data set \pm S.E.M.

Materials. Bovine trypsin was purchased from Sigma-Aldrich (Cat. No. T1426). I-191 was synthesized and characterized as described in the supplemental information. PAR2 activating peptide agonist 2f-LIGRL- $\mathrm{NH}_{2}$ and an Eu-tagged ornithine-containing peptide 2f-LIGRLO(diethylenetriaminepentaacetate-europium)- $\mathrm{NH}_{2}$ were synthesized in house, as described elsewhere (Suen et al., 2012, 2014).

\section{Results}

Inhibition of PAR2 Specific Binding in HT29 Cells. The compound I-191 (Fig. 1A) is among a series of imidazopyridazine compounds recently described in a patent application by Vertex Pharmaceuticals (Farmer et al., 2015). Here we investigate PAR2 binding, signaling, and functional properties for I-191 in HT29 human colon adenocarcinoma cells, which express higher levels of PAR2 than other PARs (Fig. 1B).

A fluorescent analog of the well-established PAR2 agonist peptide 2f-LIGRLO- $\mathrm{NH}_{2}$ (Suen et al., 2014), labeled on the ornithine sidechain with europium diethylenetriaminepentaacetate, was used in competitive binding experiments to assess specific ligand binding to PAR2. The unlabeled 2f-LIGRL-NH ${ }_{2}$ was able to compete with the Eu-tagged peptide analog for binding to HT29 cells (Fig. 1C) in a concentration-dependent manner $\left(\mathrm{pIC}_{50} 6.4 \pm 0.2\right)$. I-191 similarly displaced the
Eu-tagged peptide for binding to HT29 cells (Fig. 1C) in a concentration-dependent manner $\left(\mathrm{pIC}_{50} 7.1 \pm 0.2\right)$, consistent with specific binding of I-191 to PAR2 on HT29 cells. However, unlike 2f-LIGRL- $\mathrm{NH}_{2}$, even the highest concentrations of the antagonist I-191 did not fully displace the binding of Eu-tagged 2f-LIGLRLO- $\mathrm{NH}_{2}(\sim 25 \%$ remaining) from HT29 cells. The binding study is consistent with an insurmountable mechanism.

To investigate whether the mechanism of binding of I-191 to PAR2 was competitive or noncompetitive with a peptide agonist, we measured the binding affinity with varying concentrations of 2f-LIGRL- $\mathrm{NH}_{2}$ in the presence of Eu-tagged 2f-LIGRLO- $\mathrm{NH}_{2}(300 \mathrm{nM})$ and with increasing concentrations of I-191 (Fig. 1D). There was no significant rightward shift in the plots, and the $\mathrm{IC}_{50}$ for $2 \mathrm{f}$-LIGRL-NH was almost invariant in the presence of increasing concentrations of I-191 ( $30 \mathrm{nM}$ to $3 \mu \mathrm{M}$ ). At the highest concentrations of I-191 $(10,30 \mu \mathrm{M})$, the agonist peptide was not completely displaced (only 75\%) from the cells. This indicates that I-191 is noncompetitive with 2 f-LIGRL- $\mathrm{NH}_{2}$ in binding to PAR2 on HT29 cells.

Inhibition of PAR2-Mediated $\mathrm{Ca}^{2+}$ Release in HT29 Cells. Next, we studied I-191 for inhibition of PAR2-induced calcium signaling. I-191 was a potent antagonist in inhibiting intracellular $\mathrm{Ca}^{2+}$ release induced by either 2f-LIGRL-NH $\left(\mathrm{pIC}_{50} 7.2 \pm 0.1\right)$ or bovine trypsin $\left(\mathrm{pIC}_{50} 6.7 \pm 0.1\right)$ in HT29 cells (Fig. 2A). I-191 was an order of magnitude more potent than our previously reported antagonist GB88 under the same conditions (Fig. 2B; Table 1). I-191 did not induce any agonistinduced calcium response at concentrations up to $100 \mu \mathrm{M}$ (Fig. 2A), and it was about 100-fold more selective for PAR2 than PAR1 in PC3 cells (Supplemental Fig. 1) and HT29 cells (Farmer et al., 2015).

The duration of inhibition, reflecting receptor residence time, was determined through washout experiments using the calcium assay (Fig. 2, C and D). After 1 hour of incubation, 
A

B
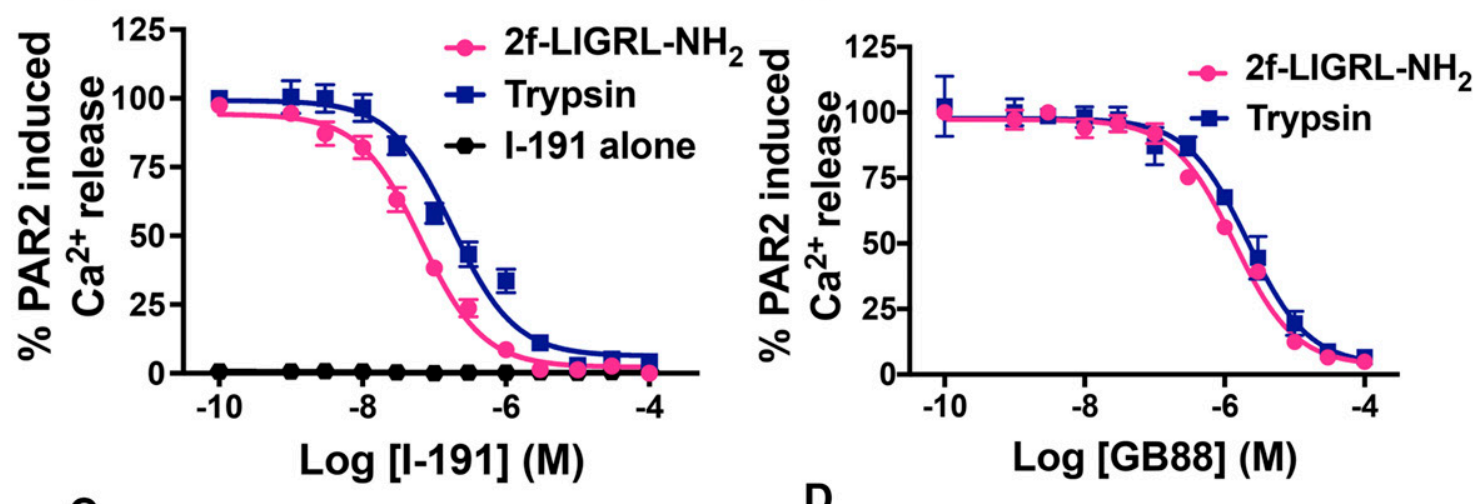

C
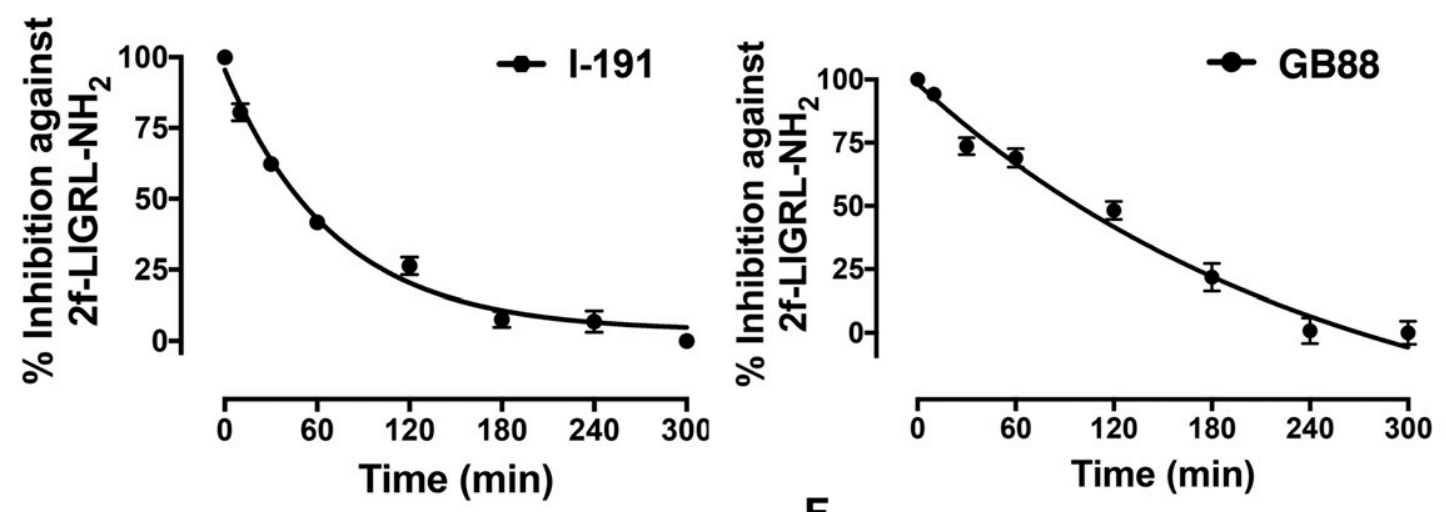

$\mathbf{E}$
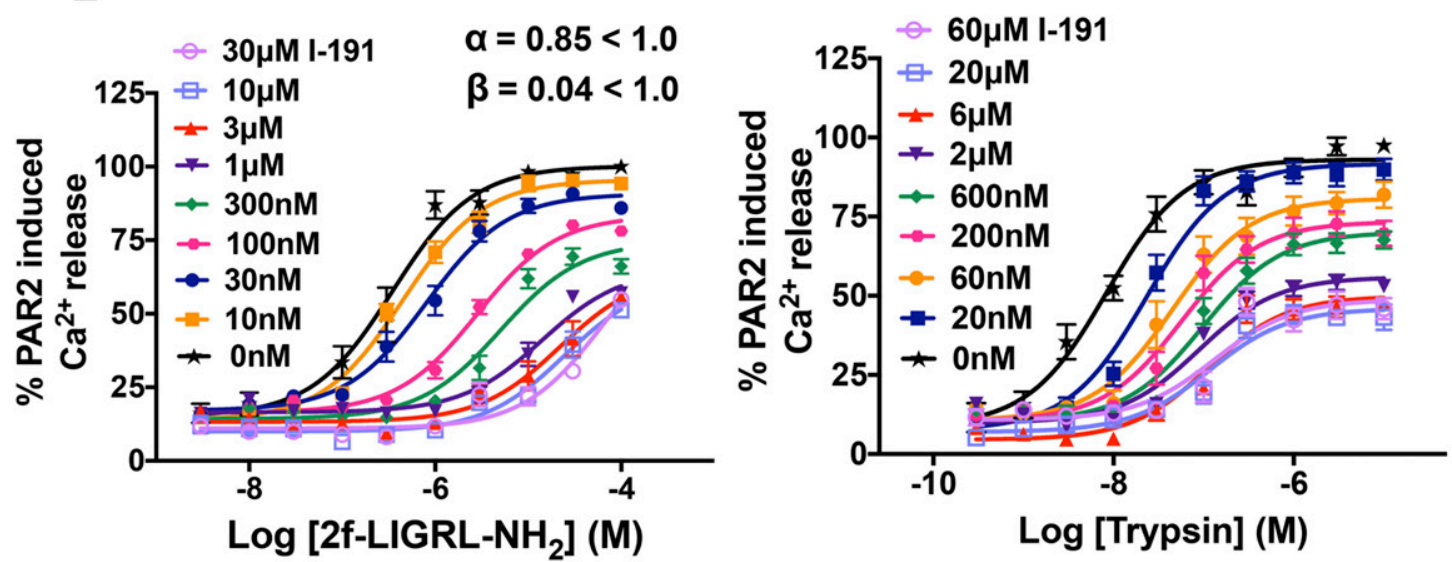

Fig. 2. I-191 attenuates PAR2-induced $\mathrm{Ca}^{2+}$ signaling in HT29 cells. (A) I-191 attenuates $\mathrm{Ca}^{2+}$ induced in HT29 cells by $5 \mu$ M $2 \mathrm{f}-\mathrm{LIGRL}-\mathrm{NH}{ }_{2}$ (pink) or $50 \mathrm{nM}$ bovine trypsin (blue), but alone shows no agonist activity (black). (B) Known antagonist GB88 similarly attenuates Ca ${ }^{2+}$ in HT29 cells but at 10 -fold higher concentrations. (C and D) Duration of inhibition by (C) I-191 $(1 \mu \mathrm{M})$ or (D) GB88 $(20 \mu \mathrm{M})$ of $\mathrm{Ca}^{2+}$ release induced by $2 \mathrm{f}-\mathrm{LIGRL}-\mathrm{NH}{ }_{2}(5 \mu \mathrm{M})$ in HT29 cells. (E) I-191 is a noncompetitive and insurmountable antagonist inhibiting $2 \mathrm{f}-\mathrm{LIGRL}-\mathrm{NH}_{2}$-induced Ca ${ }^{2+}$ release in HT29 cells. The affinity parameter $\alpha=0.85$ and efficacy parameter $\beta=0.04$ indicate that I-191 is a negative allosteric modulator of the agonist $2 \mathrm{f}-\mathrm{LIGRL}-\mathrm{NH} \mathrm{H}_{2}$. (F) I-191 is a noncompetitive and insurmountable antagonist in blocking trypsin-induced $\mathrm{Ca}^{2+}$ release in HT29 cells. Each data point representing the mean \pm S.E.M. $(n \geq 3)$.

I-191 $(1 \mu \mathrm{M})$ inhibited more than $50 \%$ of the intracellular $\mathrm{Ca}^{2+}$ release induced by $2 \mathrm{f}-\mathrm{LIGRL}-\mathrm{NH}_{2}(5 \mu \mathrm{M})$, and no antagonist activity was observed after 3 hours. The corresponding receptor residence time half-life was 51 minutes for I-191 at $37^{\circ} \mathrm{C}$, compared with $\sim 200$ minutes for GB88 $(20 \mu \mathrm{M})$. Thus, $\mathrm{I}-191$ is a potent full antagonist of PAR2 in inhibiting $\mathrm{Ca}^{2+}$ release in HT29 colon cancer cells.

The mechanism of PAR2 antagonism by I-191 was further investigated for the $\mathrm{Ca}^{2+}$ signaling pathway in HT29 cells through inhibitory effects on PAR2-induced calcium mobilization, after pretreatment of the cells with escalating concentrations of I-191. The agonist-induced calcium response curve showed a rightward shift, but a depression in the maximum response at the highest concentration of $2 \mathrm{f}-\mathrm{LIGRL}-\mathrm{NH}_{2}$ supported a noncompetitive and insurmountable mechanism of I-191 (Fig. 2E).

In addition, we measured the effect of I-191 on the $\mathrm{Ca}^{2+}$ response elicited by the native PAR2 agonist trypsin (Fig. 2F). 
TABLE 1

Comparative inhibition of PAR2-induced signals in HT29 cells

\begin{tabular}{|c|c|c|c|c|}
\hline Compound (Agonist) & $\begin{array}{c}\mathrm{iCa}^{2+} \\
\left(\mathrm{pIC}_{50} \pm \text { S.E.M. }\right)\end{array}$ & $\begin{array}{c}\mathrm{pERK1/2} \\
\left(\mathrm{pIC}_{50} \pm \text { S.E.M.) }\right.\end{array}$ & $\begin{array}{c}\text { cAMP } \\
\text { (pIC } 50 \pm \text { S.E.M.) }\end{array}$ & $\begin{array}{l}\mathrm{RhoA} \\
\left(\mathrm{pIC}_{50}\right)\end{array}$ \\
\hline I-191 (2f-LIGRL-NH $\left.{ }_{2}\right)^{a}$ & $7.2 \pm 0.1$ & $7.8 \pm 0.2$ & $6.8 \pm 0.3$ & $\sim 5.5^{e}$ \\
\hline I-191 (trypsin) $)^{b}$ & $6.7 \pm 0.1$ & $7.2 \pm 0.2$ & $6.6 \pm 0.3$ & $\sim 5.5^{e}$ \\
\hline $\mathrm{I}-191(\mathrm{~GB} 88)^{c}$ & - & $7.4 \pm 0.2$ & $6.5 \pm 0.3$ & $\sim 5.5^{e}$ \\
\hline GB88 $\left(2 \mathrm{f}-\mathrm{LIGRL}-\mathrm{NH}_{2}\right)^{d}$ & $6.0 \pm 0.1$ & - & - & - \\
\hline GB88 (trypsin) $)^{d}$ & $5.7 \pm 0.1$ & - & - & - \\
\hline
\end{tabular}

${ }^{a}$ I-191 inhibits PAR2 signaling pathways activated by 2 f-LIGRL-NH ${ }_{2}$

${ }^{b} \mathrm{I}-191$ inhibits PAR2 signaling pathways activated by bovine trypsin.

${ }^{c} \mathrm{I}-191$ inhibits PAR2 signaling pathways activated by GB88.

${ }^{d} \mathrm{~GB} 88$ inhibits $\mathrm{iCa}^{2+}$ release induced by 2 f-LIGRL-NH $\mathrm{H}_{2}$ or bovine trypsin.

${ }^{e}$ Estimated from Fig. 3B. $n \geq 3$ for all data.

The inhibitory pattern for I-191 was similar against trypsin as for 2f-LIGRL-NH $H_{2}$. Further, at 1-30 $\mu \mathrm{M}$ of I-191 against 2fLIGRL-NH $_{2}$ (Fig. 2E) or 2-60 $\mu \mathrm{M}$ I-191 against trypsin (Fig. $2 \mathrm{~F})$, no further antagonism of the $\mathrm{Ca}^{2+}$ response was obtained. This saturation effect is a hallmark of allosteric modulation. An allosteric modulator occupies its own binding site, and once the site is saturated no further allosteric antagonist effect can be achieved (Kenakin et al., 2006; Kenakin, 2007).

Using an operational model of allosterism (Gregory et al., 2012; Kenakin, 2013; Watterson et al., 2017), we calculated the cooperativity for both affinity $(\alpha)$ and efficacy $(\beta)$ of the "probe" 2f-LIGRL-NH $\mathrm{N}_{2}$ in the calcium response. The finding that $\alpha=$ $0.85<1.0$ and $\beta=0.04<1.0$ suggests that I-191 may be a negative allosteric modulator of $2 \mathrm{f}-\mathrm{LIGRL}-\mathrm{NH}_{2}$-induced PAR2 activation in $\mathrm{Ca}^{2+}$ mobilization. This calculated binding cooperativity ( $\alpha=0.85$ ) is consistent with I-191 being noncompetitive and insurmountable with the agonist probe 2f-LIGRL-NH $\mathrm{N}_{2}$. Together, the mechanistic data for binding and calcium release reveal that I-191 is a negative allosteric modulator that binds at a site on PAR2 that is distinct from 2f-LIGRL-NH 2 .

Inhibition of Other PAR2 Signaling Pathways in HT29 Cells. I-191 was also an antagonist in attenuating ERK1/2 phosphorylation (Fig. 3A) induced by either $5 \mu \mathrm{M} 2 \mathrm{f}$ LIGRL-NH ${ }_{2}\left(\mathrm{pIC}_{50} 7.8 \pm 0.2\right)$ or $50 \mathrm{nM}$ bovine trypsin $\left(\mathrm{pIC}_{50}\right.$ $7.2 \pm 0.2$ ). In addition, the agonist effect of the biased ligand GB88, which on its own stimulates ERK1/2 phosphorylation, was inhibited by I-191 $\left(\mathrm{pIC}_{50} 7.4 \pm 0.2\right)$. I-191 had greater antagonist activity in this ERK1/2 assay than in the calcium assay (5-fold greater against 2f-LIGRL-NH ${ }_{2}$ and 3-fold against trypsin), suggesting it is a more potent ERK1/2 pathway inhibitor.

Further, the PAR2 agonists 2f-LIGRL- $\mathrm{NH}_{2}$, trypsin, and the calcium-biased PAR2 antagonist GB88 each significantly stimulated RhoA activation in HT29 cells, with around a 3-fold increase compared with untreated cells (Fig. 3B). This activation of RhoA was inhibited by preincubation of HT29 cells with I-191 (10 $\mu \mathrm{M})$, highlighting I-191 as an antagonist of PAR2-mediated RhoA signaling.

I-191 was also found to stimulate an inhibition curve in PAR2 agonist-reduced forskolin-induced cAMP under certain conditions where its concentration was below $10 \mu \mathrm{M}$, suggesting that it is an antagonist in another PAR2-dependent signaling pathway (Fig. 3C).

To summarize, I-191 is the first antagonist reported to date to potently inhibit all these signaling pathways in HT29 cells.

Inhibition of PAR2-Mediated Cytokine Production and PAR2-Attenuated Cytokine-Induced Cleavage of Caspases in HT29 Cells. In addition to examining the effect of I-191 on the three different PAR2 signaling pathways, we also studied its effects on related functional responses in cancer cells. First, we investigated whether I-191 could inhibit gene expression and secretion of the inflammatory cytokine IL-8, which has been associated with ERK1/2 signaling in HT29 cells (Wang et al., 2010; Jiang et al., 2017). For gene expression (Fig. 4A), 2f-LIGRL-NH $\mathrm{NH}_{2}$ induced a 2.5-fold increase in CXCL8 mRNA expression (IL-8) in HT29 cells. I-191 ( 1 and $10 \mu \mathrm{M}$ ) decreased this expression to baseline, but lower concentrations had little effect. Similar results were observed

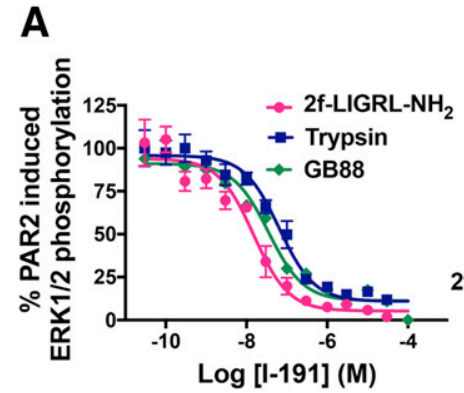

B

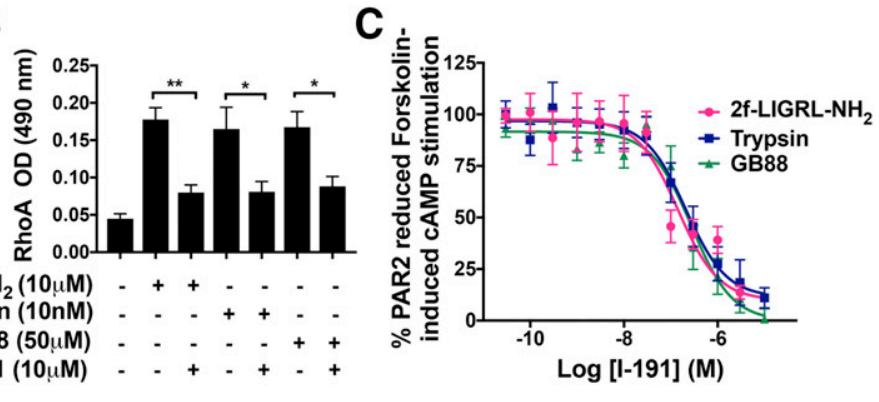

Fig. 3. I-191 inhibits PAR2-induced ERK1/2, RhoA, and cAMP signaling in HT29 cells. (A) I-191 inhibits ERK1/2 phosphorylation induced in HT29 cells by three PAR2 agonists, 2f-LIGRL-NH $(5 \mu \mathrm{M}$, pink), bovine trypsin ( $50 \mathrm{nM}$, blue) or biased ligand GB88 (10 $\mu \mathrm{M}$, green), in a concentration-dependent manner. (B) I-191 (10 $\mu \mathrm{M})$ inhibits RhoA activation induced in HT29 cells by 2 f-LIGRL-NH $2(10 \mu \mathrm{M})$, bovine trypsin $(10 \mathrm{nM})$, or GB88 (50 $\mu$ M). (C) I-191 inhibits PAR2-reduced $100 \mathrm{nM}$ forskolin-induced cAMP accumulation by $1 \mu \mathrm{M} 2 \mathrm{f}-\mathrm{LIGRL}-\mathrm{NH}_{2}$ (pink), $50 \mathrm{nM}$ bovine trypsin (blue), or $5 \mu \mathrm{M}$ GB88 (green) in a concentration-dependent manner, under conditions where the I-191 concentration was below $10 \mu \mathrm{M}$. Statistical analysis was by one-way analysis of variance followed by Dunnett's multiple comparisons test, each data point representing the mean \pm S.E.M., ${ }^{*} P<0.05 ; * * P<0.01(n \geq 3)$. 


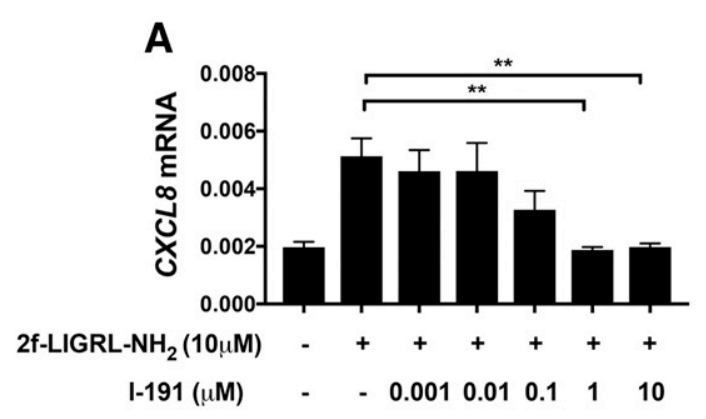

C
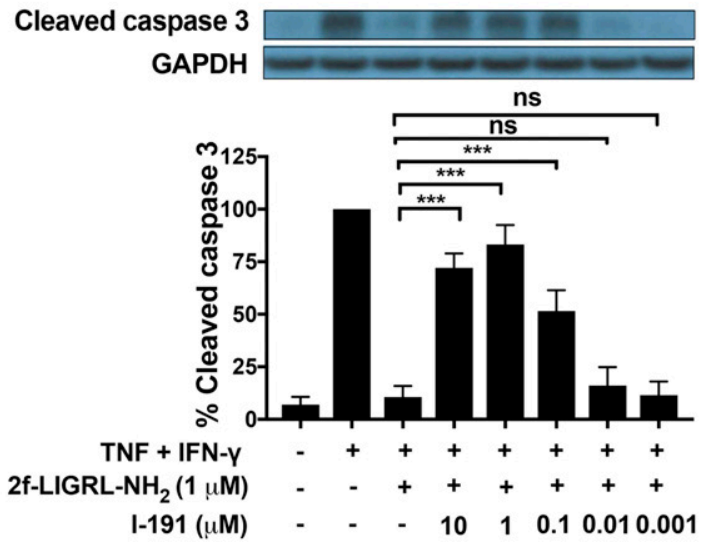
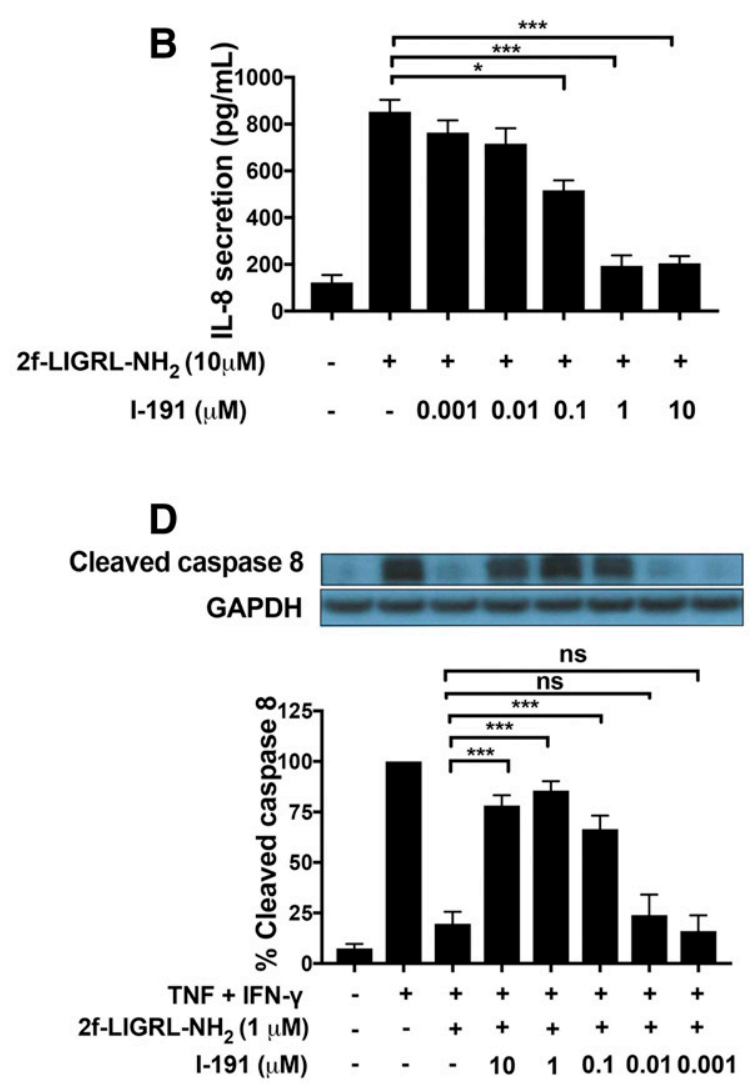

Fig. 4. I-191 inhibits PAR2-induced cytokine gene expression, cytokine protein secretion, and PAR2-inhibited cytokine-induced caspase cleavages in HT29 cells. (A and B). Concentration-dependent inhibition by I-191 of (A) CXCL8 gene expression and (B) IL-8 protein secretion induced by $2 \mathrm{f}-\mathrm{LIGRL}$ $\mathrm{NH}_{2}(10 \mu \mathrm{M})$. (C and D). PAR2 agonist 2f-LIGRL-NH $\mathrm{N}_{2}(1 \mu \mathrm{M})$ blocks apoptosis induced by the combination of IFN- $\gamma\left(40 \mathrm{ng} \mathrm{ml}^{-1}\right)$ and TNF $\left(10 \mathrm{ng} \mathrm{ml}^{-1}\right)$ through inhibiting (C) caspase 3 and (D) caspase 8 cleavages, whereas I-191 inhibits these effects in a concentration-dependent manner. Statistical analysis was by one-way analysis of variance followed by Dunnett's multiple comparisons test. $* P<0.05 ; * * P<0.01 ; * * * P<0.001(n \geq 3)$.

for IL-8 protein secretion induced by $2 \mathrm{f}-\mathrm{LIGRL}-\mathrm{NH}_{2}$, which was also inhibited by I-191 (IC $_{50} \sim 100 \mathrm{nM}$ ) (Fig. 4B).

Although PAR2 agonists do not induce expression of certain cytokines (such as IFN- $\gamma$ and TNF), they do inhibit caspase 3 and caspase 8 cleavage induced by a combination of IFN- $\gamma$ and TNF. These caspase cleavages are hallmarks of cell apoptosis in HT29 cells (Iablokov et al., 2014), and we have previously linked PAR2 inhibition of these caspase cleavages to PAR2-dependent ERK1/2 signaling in HT29 cells (Jiang et al., 2017). Here, we studied the inhibitory effect of I-191 on this PAR2 attenuation of cytokine-triggered cleavage of caspase 3 (Fig. 4C) and caspase 8 (Fig. 4D). In the presence of 2 f-LIGRL-NH $\mathrm{H}_{2}$, the IFN- $/$ /TNF combination failed to induce any caspase cleavages, but pretreatment with I-191 $(0.1,1$, or $10 \mu \mathrm{M})$ resulted in caspase cleavages. Lower concentrations of I-191 $(1,10 \mathrm{nM})$ had no effect.

These results for I-191 support the conclusion that PAR2 antagonism can inhibit cytokine production as well as cytokine-related caspase cleavages via ERK1/2 signaling in HT29 colon cancer cells.

Inhibition of PAR2-Activated Migration of HT29 Cells. Scratching of the surface of cell monolayers is a convenient and commonly used approach to measure the effects of compounds on cell migration through monitoring the capacity of the cells over time to close the scratch gap (Liang et al., 2007). This effect has also been used to screen for compounds that can promote wound healing. Recently we reported the effects of PAR2 agonists in promoting cell migration and linked this property to the ERK1/2 pathway (Jiang et al., 2017). Here, we studied whether I-191 could inhibit PAR2-mediated migration of HT29 cells into the scratch gap. In the absence of FBS, 2f-LIGRL- $\mathrm{NH}_{2}$ narrowed the scratch gap size to $\sim 60 \%$ after 24 hours and $\sim 36 \%$ after 48 hours (Fig. 5). On the other hand, I-191 showed a concentration-dependent inhibition of this narrowing, with $1 \mu \mathrm{M}$ and $10 \mu \mathrm{M}$ almost halting migration after 48 hours ( $\sim 80 \%$ ) compared with the effect of 2 f-LIGRL- $\mathrm{NH}_{2}$ alone (Fig. 5). Even $100 \mathrm{nM} \mathrm{I-191}$ could significantly reduce PAR2stimulated cell migration after 48 hours (gap size $~ 56 \%$ ), but there was no detectable effect at lower concentrations. Thus, I-191 potently attenuates PAR2 agonist-triggered migration of HT29 cells, a property we have associated with inhibition of PAR2-mediated signaling through ERK1/2 phosphorylation.

Inhibition of PAR2-Stimulated Migration and Cytokine Expression in MDA-MB-231 Breast Cancer Cells. MDA-MB-231 breast cancer cells express more PAR2 than other PARs (Fig. 6A). PAR2 is activated in MDA-MB-231 cells by the agonists 2f-LIGRL- $\mathrm{NH}_{2}$ or trypsin (Ge et al., 2004; Matej et al., 2007), and this is inhibited by I-191 (Supplemental Fig. 2). Therefore, I-191 was examined in transwell chambers to create two separate compartments for detecting PAR2-stimulated cell migration (chemotaxis).

2f-LIGRL- $\mathrm{NH}_{2}(100 \mathrm{nM})$ stimulated $\sim 3$-fold the migration of MDA-MB-231 cells (Fig. 6B). The biased antagonist GB88 

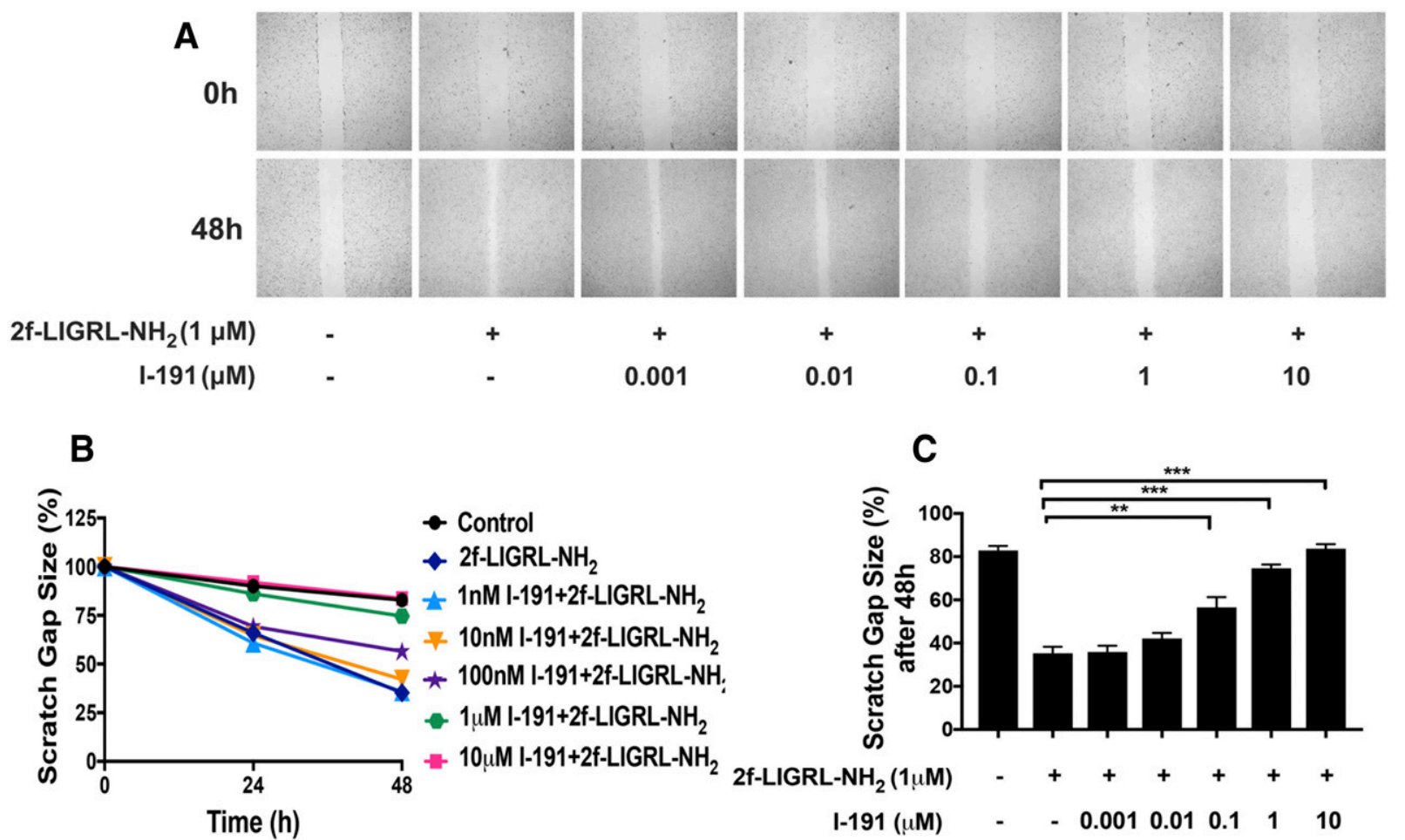

Fig. 5. I-191 attenuates PAR2-induced migration of HT29 cells in a concentration-dependent manner. (A) Concentration-dependent inhibition by I-191 of cell migration induced by PAR2 agonist 2f-LIGRL-NH $\mathrm{NH}_{2}(1 \mu \mathrm{M})$ into a scratch gap over 48 hours. (B) Temporal effect on cell migration into a scratch gap over 48 hours by 2 f-LIGRL-NH $2(1 \mu \mathrm{M})$ alone and with varying concentrations of I-191 (1, 10, $100 \mathrm{nM}$ and 1 , $10 \mu \mathrm{M})$. (C) Concentration-dependent inhibition by I-191 of cell migration over 48 hours induced by PAR2 agonist 2 f-LIGRL-NH $\mathrm{N}_{2}(1 \mu \mathrm{M})$ into a scratch gap. Statistical analysis was by one-way analysis of variance followed by Dunnett's multiple comparisons test. $* * P<0.01$; ***P $<0.001(n \geq 3)$.

(3, $10 \mu \mathrm{M})$ that only inhibits the $\mathrm{Gq}-\mathrm{Ca}^{2+}$-PKC signaling pathway (Suen et al., 2014) did not inhibit PAR2-mediated migration, nor was it an agonist alone in inducing migration (Supplemental Fig. 3). In contrast, pretreatment with I-191 $(1 \mu \mathrm{M})$ led to inhibition of the migration of MDA-MB-231 cells induced by 2 f-LIGRL-NH ${ }_{2}$ (Fig. 6B).

Further, four important signaling proteins that regulate physiological responses were used to probe the effect of I-191 (Fig. 6, C-F). 2f-LIGRL-NH ${ }_{2}$ significantly enhances gene expression of interleukin 6 (IL6, 25-fold increase), IL-8 (CXCL8, 90-fold increase), connective tissue growth factor (CTGF, 6-fold increase), and granulocyte macrophage colony-stimulating factor (CSF2, 14-fold increase) in MDAMB-231 cells. I-191 (10 or $1 \mu \mathrm{M})$ significantly inhibited the expression of all four cytokine genes induced by $2 \mathrm{f}$ LIGRL-NH . $_{2}$

These data for breast cancer cells are consistent with earlier findings for colorectal carcinoma cells, supporting I-191 as an inhibitor of PAR2-induced chemotaxis and cytokine production in MDA-MB-231 breast cancer cells.

\section{Discussion}

GPCRs play pivotal roles in cellular sensing and intracellular responses to extracellular ligands (Marinissen and Gutkind, 2001). About 30\% of all pharmaceuticals target GPCRs and were developed to either turn their functions on or off. However, each membrane-spanning GPCR protein is linked to multiple G-protein-dependent and -independent signaling pathways, in turn linked to different physiological functions. Thus, although switching a GPCR on or off was once thought to activate all or none of the associated signaling pathways and functional responses linked to that GPCR, we now know that some ligands exhibit biased signaling and activate or inhibit only one or a subset of these pathways and functions. Biased signaling was originally thought to involve either G protein coupling or beta arrestin signaling, but it is now known to apply to differential modulation of all individual pathways linked to a GPCR (Hollenberg et al., 2014; Suen et al., 2014; Rankovic et al., 2016). It is therefore conceivable that ligands can be developed to modulate one or a few signaling pathways linked to a GPCR without affecting other pathways, or at least without similarly affecting all other signaling and functional responses. Indeed, antagonists may even be more beneficial if they only inhibited a single GPCRlinked pathway associated with a disease, without inhibiting other pathways linked to the same GPCR but responsible for beneficial functional responses in the cell.

In the context of PAR2, it would be useful to have antagonists that can block all PAR2-mediated signal transduction, as well as antagonists that block just one or a few downstream signaling pathways (Suen et al., 2014). They could be helpful molecular tools for teasing out the relative merits of complete versus selective blockade of individual PAR2-linked signaling pathways in cells. In disease settings like cancer, where PAR2 is highly expressed it may be more desirable to inhibit multiple PAR2-dependent signaling associated with metastasis, proliferation, angiogenesis, and other functions promoting tumor development (Dorsam and Gutkind, 2007; Chang et al., 2013; Xie et al., 2015; Chanakira 
A

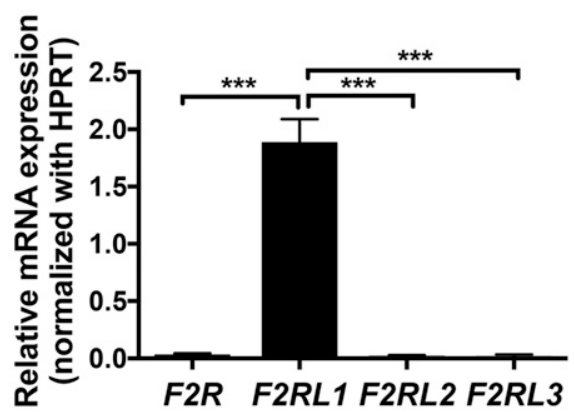

B

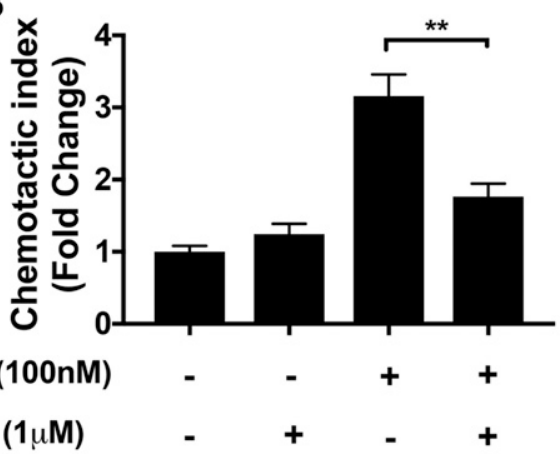

D

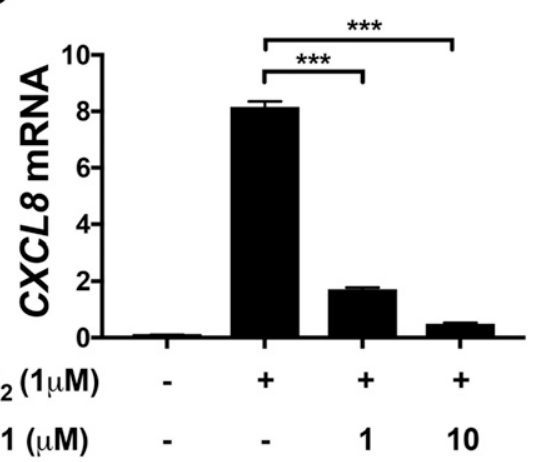

$\mathbf{F}$

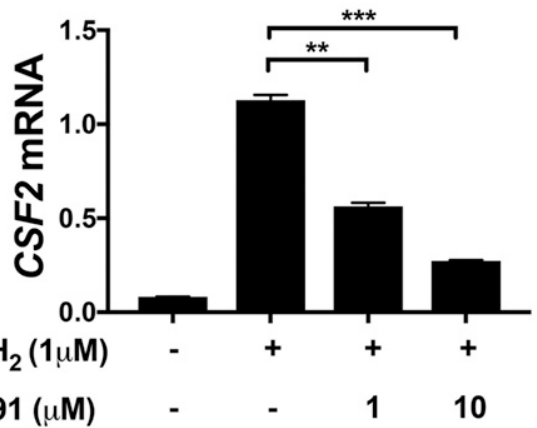

Fig. 6. I-191 inhibits PAR2-induced migration and cytokine gene expression in MDA-MB-231 cells. (A) Cells expressed the PAR2 mRNA more highly than PAR1, PAR3, and PAR4. (B) Cell migration induced by PAR2 agonist 2f-LIGRL-NH 2 (100 nM) is inhibited by I-191 ( $1 \mu \mathrm{M})$. (C and F) $2 \mathrm{f}-L I G R L-N H_{2}$ $(1 \mu \mathrm{M})$ induces mRNA expression of (C) IL6, (D) CXCL8, (E) CTGF, or (F) CSF2, which are inhibited by I-191 (1 or $10 \mu \mathrm{M})$. Statistical analysis was by one-way analysis of variance followed by Dunnett's multiple comparisons test. ${ }^{*} P<0.05$; $* * P<0.01$; $* * * P<0.001(n \geq 3)$.

et al., 2017), whereas in other settings it may be more desirable to dampen some signaling such as that leading to proinflammatory functions while still engaging signaling that leads to beneficial anti-inflammatory actions.

To date, no antagonists have been found to potently inhibit all types of PAR2 agonists (proteases, peptides, nonpeptide), nor has any antagonist been shown to potently inhibit all known signaling pathways and functions activated by PAR2. Here we investigated whether a new imidazopyridazine compound I-191 (Farmer et al., 2015) binds to PAR2 and acts as an antagonist of different agonists; we studied the mechanism of antagonism and whether it inhibits multiple PAR2 signaling functions or only blocks one or a subset of PAR2 signaling responses like GB88 (Suen et al., 2014).

This study provides evidence that I-191 binds to PAR2; it acts in a concentration-dependent manner to displace a PAR2 ligand, fluorescence-labeled 2f-LIGRLO-NH${ }_{2}$, for binding to PAR2 in HT29 colon cancer cells. I-191 had a surprisingly short residence time on PAR2 (Fig. 2C) but was still able to attenuate calcium release induced in HT29 cells by either a proteolytic (trypsin) or peptidic (2f-LIGRL- $\mathrm{NH}_{2}$.) agonist of PAR2. The potency of I-191 was about 10-fold higher than the antagonist GB88 under the same conditions (Table 1). Furthermore, I-191 showed no agonist activity even at high micromolar concentrations. This capacity to antagonize both proteolytic and nonproteolytic agonists of PAR2, as well as not displaying agonist activity at high concentrations, is not shared by all reported antagonists of PAR2 (Yau et al., 2013).

The antagonist mechanism for I-191 was also investigated. I-191 inhibited the binding of Eu-tagged 2f-LIGRLO- $\mathrm{NH}_{2}$ to PAR2 in a concentration-dependent manner, but it could not completely displace the agonist even at high concentrations. 


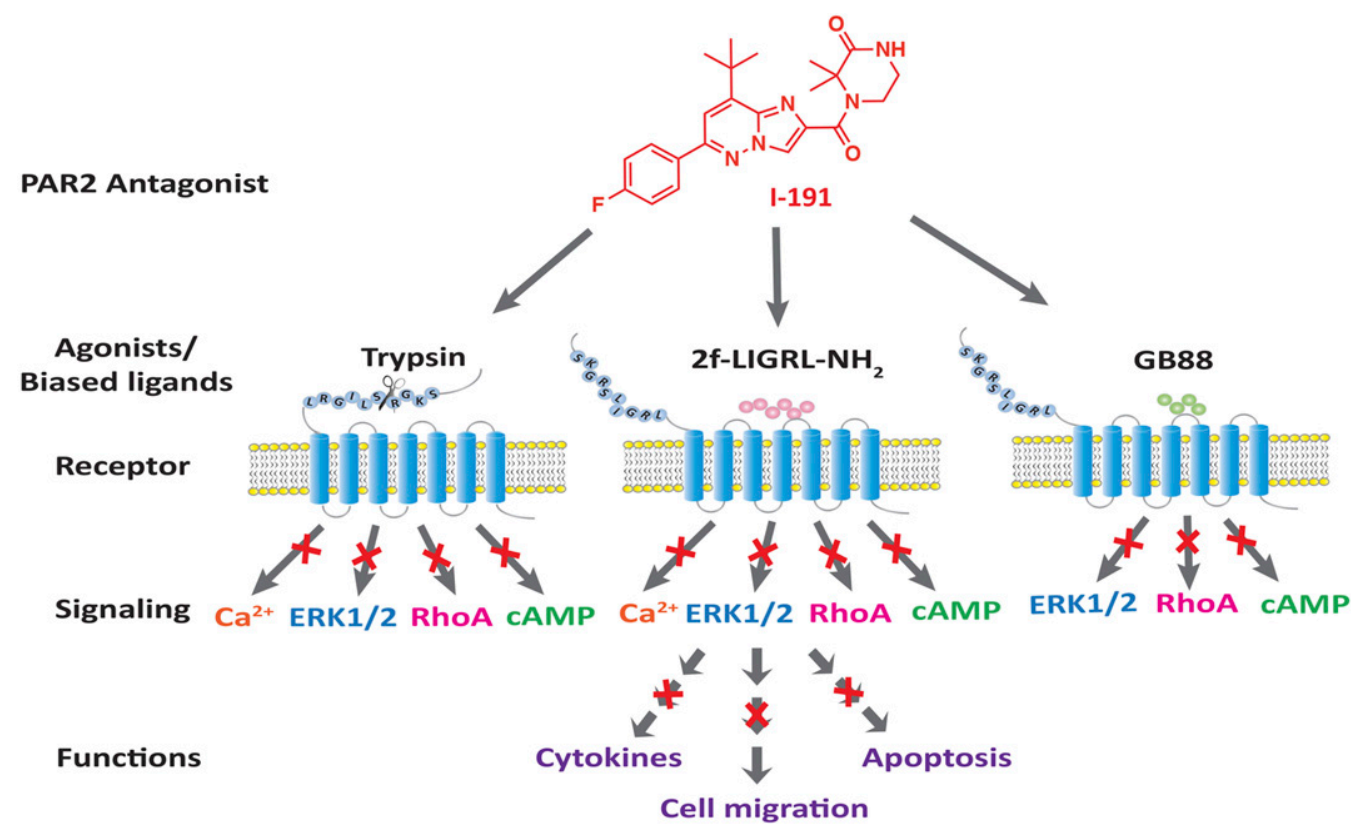

Fig. 7. Effect of I-191 (red cross) on intracellular signaling and cell functions induced by three different types of PAR2 agonist.

This noncompetitive and insurmountable binding suggested that I-191 may be an allosteric modulator (Christopoulos, 2002). Increasing concentrations of I-191 in PAR2 agonistinduced calcium release revealed a saturation phenomenon, supporting allosteric binding of I-191 to PAR2.

A characteristic of allosterism is cooperativity between orthosteric and allosteric ligands, known as "probe dependence" (Valant et al., 2012). Allosteric modulators can use different mechanisms of inhibition against different agonists of GPCRs (Watterson et al., 2017). However, for PARs it is difficult to characterize allosteric mechanisms because there is no exogenous orthosteric ligand. Instead it is the protease-cleaved $\mathrm{N}$ terminus of the receptor itself that acts as the tethered orthosteric agonist. Therefore, the close surrogate 2f-LIGRL$\mathrm{NH}_{2}$ was used as an agonist, and the definition of orthosteric versus allosteric relates specifically to whether I-191 binds to the same or different site on PAR2 as 2f-LIGRL-NH $\mathrm{N}_{2}$ I-191 proved to be a negative allosteric modulator $(\alpha=0.85<1.0, \beta=$ $0.04<1.0$ ) of 2 f-LIGRL- $\mathrm{NH}_{2}$ based on an operational model of allosterism (Gregory et al., 2012; Kenakin, 2013).

This mechanistic interpretation needs qualification. First, the agonist is not the endogenous PAR2 agonist. Most synthetic agonists are analogs of the tethered sequence SLIGKV, such as SLIGRL-NH ${ }_{2}$, 2f-LIGRL-NH ${ }_{2}$, GB110, and AY77(5-Isoxazoyl-Cha-Chg- $\mathrm{NH}_{2}$ ). Structurally diverse PAR2 agonists may enhance our understanding of PAR2 activation mechanisms and permit better mechanistic descriptions of antagonist mechanisms. Second, $\mathrm{Ca}^{2+}$ mobilization induced

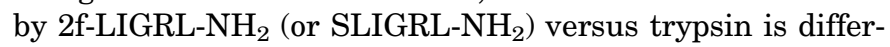
entially influenced by PAR2 mutagenesis (Suen et al., 2017), suggesting that even synthetic peptide agonists might bind to a different site on PAR2 than the tethered ligand unmasked by trypsin. Our results indicate that I-191 is a negative allosteric modulator that may bind at a site on PAR2 that is different from that occupied by $2 \mathrm{f}-\mathrm{LIGRL}-\mathrm{NH}_{2}$ or tethered agonist. Third, allosteric behavior is context dependent, and these ligands may behave differently under different conditions, in other cell types and signaling pathways (Gao and Jacobson, 2017). The description here of allosteric modulation may be context and system dependent.

I-191 is also the first PAR2 antagonist reported to potently inhibit ERK1/2 phosphorylation, RhoA and cAMP activation induced by PAR2 agonists. Three different PAR2 agonists (trypsin, 2f-LIGRL-NH $\mathrm{NH}_{2}$ GB88) were used to produce these reporters in HT29 cells and to measure inhibition by I-191. I-191 is also the first antagonist reported to inhibit PAR2 activation of ERK1/2, RhoA, and cAMP by the biased ligand GB88. It was a more potent antagonist than the recently reported $\mathrm{C} 391$ ( $\mathrm{IC}_{50} 14 \mu \mathrm{M}, \mathrm{pERK} 1 / 2$ ) (Boitano et al., 2015). RhoA and cAMP signaling is mediated by PAR2 activation (Greenberg et al., 2003; Sriwai et al., 2013; Suen et al., 2014), but no PAR2 antagonist has been reported to inhibit this pathway until now.

Finally, we demonstrate that I-191 antagonizes different cellular functions stimulated by PAR2 agonists in colon and breast cancer cells. PAR2 activation is known to induce migration, cytokine release, and apoptosis in HT29 cells (Darmoul et al., 2004; Wang et al., 2010; Iablokov et al., 2014). PAR2 agonists may thus have some benefit in promoting cell survival in normal cells, whereas antagonists might promote apoptosis but inhibit cytokine release in, and migration of, cancer cells and prevent disease progression. I-191 was found here to affect three PAR2-intiated functions linked previously to ERK1/2 phosphorylation in HT29 cells (Jiang et al., 2017). Consistent with I-191 being a potent PAR2 antagonist of ERK1/2 phosphorylation in HT29 cells, I-191 was found to inhibit 1) PAR2 agonist-induced IL-8 gene expression and protein secretion, 2) PAR2 agonist-attenuation of IFN- $\gamma / \mathrm{TNF}$-induced caspase $3 / 8$ cleavages related to apoptosis, and 3) cell migration into a scratch gap in HT29 cell monolayers.

Breast cancer progression and metastasis is another consequence of PAR2 activation (Ge et al., 2004; Matej et al., 2007; Parisis et al., 2013). PAR2 is overexpressed in $72 \%$ of breast cancer tissues but only $21 \%$ of normal tissues. MDA-MB-231 
cells overexpress PAR2 and migrate along a PAR2 agonist gradient (Su et al., 2009). The inhibitory effects of I-191 on PAR2-induced migration of MDA-MB-231 breast cancer cells are consistent with observations for HT29 colon cancer cells, indicating potent antagonist properties in different cancer cell lines. Unlike the biased ligand GB88, which does not inhibit ERK1/2 activation or PAR2-induced migration, I-191 strongly inhibited 2f-LIGRL-NH ${ }_{2}$-induced migration of MDA-MB-231 cells. When MDA-MB-231 cells were pretreated with I-191, the latter antagonized $2 \mathrm{f}-\mathrm{LIGRL}-\mathrm{NH}_{2}-$ stimulated expression of cytokines (IL-6, IL-8, granulocyte macrophage colonystimulating factor, CTGF). I-191 also inhibited PAR2induced calcium release in normal human cells that highly express PAR2, such as HEK293 and HUVEC cells, but was not cytotoxic (Supplemental Fig. 4).

In conclusion, this study supports I-191 as a potent, unbiased and full antagonist of human PAR2 in cancer cell lines. It inhibited PAR2-induced signaling activated in vitro by three different types of PAR2 agonists (protease, peptide, nonpeptide). It is the first potent antagonist in vitro of PAR2mediated intracellular signaling through different pathways in HT29 cells, namely $\mathrm{Ca}^{2+}$ mobilization, ERK1/2 phosphorylation, RhoA activation, and foskolin-induced cAMP accumulation. These PAR2 antagonist properties are manifested in inhibition in vitro of known PAR2-activated functional responses, namely cytokine expression, apoptosis, and cell migration in colorectal or breast cancer cells (Fig. 7). This establishes I-191 as a potentially valuable new molecular tool for interrogating and better understanding the roles of PAR2 in physiology and disease settings, and this study could lay the groundwork for developing a new therapeutic agent for treating PAR2-mediated diseases.

\section{Acknowledgments}

The authors thank Kum Kum Khanna and Dr. Glenn Boyle (Queensland Institute of Medical Research, Brisbane, Australia) for MDA-MB-231 and HT29 cells, respectively, and the Australian Cancer Research Foundation (ACRF) for a Cancer Biology Imaging Facility (Brisbane, Qld, Australia) enabling access to microscopes.

\section{Authorship Contributions}

Participated in research design: Jiang, Yau, Lim, Suen, Fairlie.

Conducted experiments: Jiang, Yau, Lim, Wu.

Contributed new reagents or analytic tools: Yau.

Performed data analysis: Jiang, Xu, Yau, Lim, Wu, Fairlie.

Wrote or contributed to the writing of the manuscript: Jiang, Yau, Lim, Wu, Xu, Suen, Fairlie.

\section{References}

Arora P, Ricks TK, and Trejo J (2007) Protease-activated receptor signalling, endocytic sorting and dysregulation in cancer. J Cell Sci 120:921-928.

Barry GD, Suen JY, Le GT, Cotterell A, Reid RC, and Fairlie DP (2010) Novel agonists and antagonists for human protease activated receptor 2. J Med Chem 53: $7428-7440$

Boitano S, Hoffman J, Flynn AN, Asiedu MN, Tillu DV, Zhang Z, Sherwood CL, Rivas CM DeFea KA, Vagner J, et al. (2015) The novel PAR2 ligand C391 blocks multiple PAR2 signalling pathways in vitro and in vivo. Br J Pharmacol 172:4535-4545.

Chanakira A, Westmark PR, Ong IM, and Sheehan JP (2017) Tissue factor-factor VII a complex triggers protease activated receptor 2-dependent growth factor release and migration in ovarian cancer. Gynecol Oncol 145:167-175.

Chang LH, Pan SL, Lai CY, Tsai AC, and Teng CM (2013) Activated PAR-2 regulates pancreatic cancer progression through ILK/HIF- $\alpha$-induced TGF- $\alpha$ expression and MEK/VEGF-A-mediated angiogenesis. Am J Pathol 183:566-575.

Cheng RKY, Fiez-Vandal C, Schlenker O, Edman K, Aggeler B, Brown DG, Brown GA, Cooke RM, Dumelin CE, Doré AS, et al. (2017) Structural insight into allosteric modulation of protease-activated receptor 2. Nature 545:112-115.

Christopoulos A (2002) Allosteric binding sites on cell-surface receptors: novel targets for drug discovery. Nat Rev Drug Discov 1:198-210.

Coughlin SR (2000) Thrombin signalling and protease-activated receptors. Nature 407:258-264.
Darmoul D, Gratio V, Devaud H, and Laburthe M (2004) Protease-activated receptor 2 in colon cancer: trypsin-induced MAPK phosphorylation and cell proliferation are mediated by epidermal growth factor receptor transactivation. J Biol Chem $\mathbf{2 7 9}$ 20927-20934.

Dorsam RT and Gutkind JS (2007) G-protein-coupled receptors and cancer. Nat Rev Cancer 7:79-94.

Farmer LJ, Fournier PA, Lessard S, Liu B, St-Onge M, Sturino C, Szychowski J, Yannopoulos C, Vallee F, Lacoste JE, et al. (2015) inventors, Vertex Pharmaceuticals Incorporated, assignee. Imidazopyridazines useful as inhibitors of the PAR-2 signaling pathway. WIPO Patent WO2015048245. 2015 Apr 2.

Gao ZG and Jacobson KA (2017) Distinct signaling patterns of allosteric antagonism at the P2Y1 receptor. Mol Pharmacol 92:613-626.

Ge L, Shenoy SK, Lefkowitz RJ, and DeFea K (2004) Constitutive protease-activated receptor-2-mediated migration of MDA MB-231 breast cancer cells requires both beta-arrestin-1 and -2. J Biol Chem 279:55419-55424.

Goh FG, Ng PY, Nilsson M, Kanke T, and Plevin R (2009) Dual effect of the novel peptide antagonist K-14585 on proteinase-activated receptor-2-mediated signalling. Br J Pharmacol 158:1695-1704.

Greenberg DL, Mize GJ, and Takayama TK (2003) Protease-activated receptor mediated RhoA signaling and cytoskeletal reorganization in $\mathrm{LNCaP}$ cells. Biochemistry 42:702-709.

Gregory KJ, Noetzel MJ, Rook JM, Vinson PN, Stauffer SR, Rodriguez AL, Emmitte KA, Zhou Y, Chun AC, Felts AS, et al. (2012) Investigating metabotropic glutamate receptor 5 allosteric modulator cooperativity, affinity, and agonism: enriching structure-function studies and structure-activity relationships. Mol Pharmacol 82: $860-875$

Hoffman J, Flynn AN, Tillu DV, Zhang Z, Patek R, Price TJ, Vagner J, and Boitano S (2012) Lanthanide labeling of a potent protease activated receptor-2 agonist for time-resolved fluorescence analysis. Bioconjug Chem 23:2098-2104.

Hollenberg MD, Mihara K, Polley D, Suen JY, Han A, Fairlie DP, and Ramachandran $\mathrm{R}$ (2014) Biased signalling and proteinase-activated receptors (PARs): targeting inflammatory disease. $\mathrm{Br}$ J Pharmacol 171:1180-1194.

Iablokov V, Hirota CL, Peplowski MA, Ramachandran R, Mihara K, Hollenberg MD, and MacNaughton WK (2014) Proteinase-activated receptor 2 (PAR2) decreases apoptosis in colonic epithelial cells. J Biol Chem 289:34366-34377.

Jiang Y, Yau M-K, Kok WM, Lim J, Wu K-C, Liu L, Hill TA, Suen JY, and Fairlie DP (2017) Biased signaling by agonists of protease activated receptor 2. ACS Chem Biol 12:1217-1226.

Kawabata A, Oono Y, Yonezawa D, Hiramatsu K, Inoi N, Sekiguchi F, Honjo M, Hirofuchi M, Kanke T, and Ishiwata H (2005) 2-Furoyl-LIGRL-NH2, a potent agonist for proteinase-activated receptor-2, as a gastric mucosal cytoprotective agent in mice. $\mathrm{Br} J$ Pharmacol 144:212-219.

Kelso EB, Lockhart JC, Hembrough T, Dunning L, Plevin R, Hollenberg MD, Sommerhoff CP, McLean JS, and Ferrell WR (2006) Therapeutic promise of proteinase-activated receptor-2 antagonism in joint inflammation. J Pharmacol Exp Ther 316:1017-1024.

Kenakin T (2007) Allosteric theory: taking therapeutic advantage of the malleable nature of GPCRs. Curr Neuropharmacol 5:149-156.

Kenakin T (2013) Analytical pharmacology and allosterism: the importance of quantifying drug parameters in drug discovery. Drug Discov Today Technol 10: $\mathrm{e} 229-\mathrm{e} 235$.

Kenakin T, Jenkinson S, and Watson C (2006) Determining the potency and molecular mechanism of action of insurmountable antagonists. J Pharmacol Exp Ther 319:710-723.

Knight DA, Lim S, Scaffidi AK, Roche N, Chung KF, Stewart GA, and Thompson PJ (2001) Protease-activated receptors in human airways: upregulation of PAR-2 in respiratory epithelium from patients with asthma. J Allergy Clin Immunol 108: 797-803

Lam DK and Schmidt BL (2010) Serine proteases and protease-activated receptor 2-dependent allodynia: a novel cancer pain pathway. Pain 149:263-272.

Liang C-C, Park AY, and Guan J-L (2007) In vitro scratch assay: a convenient and inexpensive method for analysis of cell migration in vitro. Nat Protoc 2:329-333.

Marinissen MJ and Gutkind JS (2001) G-protein-coupled receptors and signaling networks: emerging paradigms. Trends Pharmacol Sci 22:368-376.

Matej R, Mandáková P, Netíková I, Poucková P, and Olejár T (2007) Proteinaseactivated receptor-2 expression in breast cancer and the role of trypsin on growth and metabolism of breast cancer cell line MDA MB-231. Physiol Res 56: 475-484

McLarty JL, Meléndez GC, Brower GL, Janicki JS, and Levick SP (2011) Tryptase/ Protease-activated receptor 2 interactions induce selective mitogen-activated protein kinase signaling and collagen synthesis by cardiac fibroblasts. Hypertension 58:264-270.

Mihara K, Ramachandran R, Saifeddine M, Hansen KK, Renaux B, Polley D, Gibson S, Vanderboor C, and Hollenberg MD (2016) Thrombin-mediated direct activation of proteinase-activated receptor-2: another target for thrombin signaling. Mol Pharmacol 89:606-614.

Ossovskaya VS and Bunnett NW (2004) Protease-activated receptors: contribution to physiology and disease. Physiol Rev 84:579-621.

Parisis N, Metodieva G, and Metodiev MV (2013) Pseudopodial and $\beta$-arrestininteracting proteomes from migrating breast cancer cells upon PAR2 activation. $J$ Proteomics 80:91-106.

Ramachandran R, Mihara K, Chung H, Renaux B, Lau CS, Muruve DA, DeFea KA, Bouvier M, and Hollenberg MD (2011) Neutrophil elastase acts as a biased agonist for proteinase-activated receptor-2 (PAR2). J Biol Chem 286:24638-24648.

Rankovic Z, Brust TF, and Bohn LM (2016) Biased agonism: an emerging paradigm in GPCR drug discovery. Bioorg Med Chem Lett 26:241-250.

Reed DE, Barajas-Lopez C, Cottrell G, Velazquez-Rocha S, Dery O, Grady EF, Bunnett NW, and Vanner SJ (2003) Mast cell tryptase and proteinase-activated receptor 2 induce hyperexcitability of guinea-pig submucosal neurons. $J$ Physiol 547:531-542. 
Rothmeier AS and Ruf W (2012) Protease-activated receptor 2 signaling in inflammation. Semin Immunopathol 34:133-149.

Saito T and Bunnett NW (2005) Protease-activated receptors: regulation of neuronal function. Neuromolecular Med 7:79-99.

Seitz I, Hess S, Schulz H, Eckl R, Busch G, Montens HP, Brandl R, Seidl S, Schömig A, and Ott I (2007) Membrane-type serine protease-1/matriptase induces interleukin-6 and -8 in endothelial cells by activation of protease-activated receptor-2: potential implications in atherosclerosis. Arterioscler Thromb Vasc Biol 27:769-775.

Sriwai W, Mahavadi S, Al-Shboul O, Grider JR, and Murthy KS (2013) Distinctive G protein-dependent signaling by protease-activated receptor 2 (PAR2) in smooth muscle: feedback inhibition of RhoA by cAMP-independent PKA. PLoS One 8: e66743.

Su S, Li Y, Luo Y, Sheng Y, Su Y, Padia RN, Pan ZK, Dong Z, and Huang S (2009) Proteinase-activated receptor 2 expression in breast cancer and its role in breast cancer cell migration. Oncogene 28:3047-3057.

Suen JY, Adams MN, Lim J, Madala PK, Xu W, Cotterell AJ, He Y, Yau M-K, Hooper JD, and Fairlie DP (2017) Mapping transmembrane residues of proteinase activated receptor 2 (PAR2) that influence ligand-modulated calcium signaling. Pharmacol Res 117:328-342.

Suen JY, Barry GD, Lohman RJ, Halili MA, Cotterell AJ, Le GT, and Fairlie DP (2012) Modulating human proteinase activated receptor 2 with a novel antagonist (GB88) and agonist (GB110). Br J Pharmacol 165:1413-1423.

Suen JY, Cotterell A, Lohman RJ, Lim J, Han A, Yau MK, Liu L, Cooper MA, Vesey DA, and Fairlie DP (2014) Pathway-selective antagonism of proteinase activated receptor 2. Br J Pharmacol 171:4112-4124.

Tuteja N (2009) Signaling through G protein coupled receptors. Plant Signal Behav 4 942-947.

Valant C, Felder CC, Sexton PM, and Christopoulos A (2012) Probe dependence in the allosteric modulation of a $\mathrm{G}$ protein-coupled receptor: implications for detection and validation of allosteric ligand effects. Mol Pharmacol 81:41-52.
Wang H, Moreau F, Hirota CL, and MacNaughton WK (2010) Proteinase-activated receptors induce interleukin-8 expression by intestinal epithelial cells through ERK/RSK90 activation and histone acetylation. FASEB $J$ 24:1971-1980.

Watterson KR, Hansen SVF, Hudson BD, Alvarez-Curto E, Raihan SZ, Azevedo CMG, Martin G, Dunlop J, Yarwood SJ, Ulven T, et al. (2017) Probe-dependent negative allosteric modulators of the long-chain free fatty acid receptor FFA4. Mol Pharmacol 91:630-641.

Xie L, Duan Z, Liu C, Zheng Y, and Zhou J (2015) Protease-activated receptor 2 agonist increases cell proliferation and invasion of human pancreatic cancer cells. Exp Ther Med 9:239-244.

Yau M-K, Lim J, Liu L, and Fairlie DP (2016a) Protease activated receptor 2 (PAR2) modulators: a patent review (2010-2015). Expert Opin Thera Pat 26:471-483.

Yau MK, Liu L, and Fairlie DP (2013) Toward drugs for protease-activated receptor 2 (PAR2). J Med Chem 56:7477-7497.

Yau M-K, Liu L, Suen JY, Lim J, Lohman R-J, Jiang Y, Cotterell AJ, Barry GD, Mak JYW, Vesey DA, et al. (2016b) PAR2 modulators derived from GB88. ACS Med Chem Lett 7:1179-1184.

Yau M-K, Suen JY, Xu W, Lim J, Liu L, Adams MN, He Y, Hooper JD, Reid RC, and Fairlie DP (2015) Potent small agonists of protease activated receptor 2. ACS Med Chem Lett 7:105-110.

Zhao P, Lieu T, Barlow N, Sostegni S, Haerteis S, Korbmacher C, Liedtke W, JimenezVargas NN, Vanner SJ, and Bunnett NW. (2015) Neutrophil elastase activates PAR2 and TRPV4 to cause inflammation and pain. J Biol Chem 290:13875-13887.

Address correspondence to: David P. Fairlie, Centre for Inflammation and Disease Research and Australian Research Council Centre of Excellence in Advanced Molecular Imaging, Institute for Molecular Bioscience, The University of Queensland, Brisbane, Qld 4072, Australia. E-mail: d.fairlie@ imb.uq.edu.au 